\section{Odontología Sanmarquina amplía sus fronteras}

\author{
Odontología Sanmarquina \\ expands its borders
}

Manuel Antonio Mattos-Vela ${ }^{1, a, b}$, Luis Cuadrao Zavaleta ${ }^{1, a, c}$

${ }^{1}$ Universidad Nacional Mayor de San Marcos. Facultad de Odontología. Lima, Perú.

a Doctor en Estomatología

${ }^{\text {b }}$ Editor general de la revista Odontología Sanmarquina

c Director de la revista Odontología Sanmarquina

Correspondencia:

Manuel Antonio Mattos-Vela

Correo electrónico: mmattosv@unmsm.edu.pe

Universidad Nacional Mayor de San Marcos, Facultad de Odontología. Calle Germán Amézaga 375. Lima 1, Perú.

Coautor:

Luis Cuadrao Zavaleta

Icuadraoz@unmsm.edu.pe

Fecha de recepción: 19/05/18

Fecha de aceptación: 29/05/18
La internacionalización de una revista implica que el alcance de esta cubra la comunidad científica de diversos países, no solo a nivel de los autores que publican en ella, sino también de su equipo editorial, revisores y lectores. Tal vez, la indización de una revista en una base de datos internacional sea la culminación de este proceso ${ }^{1,2}$.

Odontología Sanmarquina aspira a transformarse de una revista institucional a una internacional. Sabemos que este proceso toma tiempo y requiere mucho esfuerzo. Involucra una mejora continua en la calidad de sus contenidos y procesos editoriales. Estamos dando pasos en esta dirección y a partir de los cambios en la estructura de la revista, en sus procesos editoriales, en el equipo editor y las estrategias implementadas a partir del 2017 3,4 estamos cosechando resultados importantes que nos gustaría compartir con ustedes.

Aumento en el flujo de manuscritos recibidos para revisión: considerando solamente artículos originales, de revisión y casos clínicos, el 2017 recibimos 52 manuscritos, en estos primeros cuatro meses y medio del 2018 ya hemos recibido 43 manuscritos.

Aumento en la proporción de manuscritos recibidos y artículos publicados externos a nuestra institución: en el 2017 el 62\% de los manuscritos recibidos fueron externos y el $66 \%$ de ellos internacionales. En estos primeros meses del 2018 el 86\% son externos, de estos el 95\% son internacionales. Estos manuscritos han provenido de 11 países extranjeros. En cuanto a los artículos publicados en Odontología Sanmarquina, en el 2015 y 2016 el $27 \%$ fueron externos a nuestra institución, siendo la mayoría de ellos nacionales. En el 2017 el 60\% fueron externos, siendo la mayoría internacionales.

Aumento de los integrantes del Comité Consultivo: hace poco ingresaron cinco nuevos miembros, con los cuales contamos ya con 24 integrantes, todos ellos son externos a nuestras institución (la gran mayoría extranjeros) y referentes de la Odontología en la disciplina que desarrollan, cuya misión es asesorar al Comité Editor en temas de política y proceso editorial, opinar sobre los contenidos de la revista, escribir editoriales, sugerir revisores y actuar de revisores de manuscritos. Está pendiente la tarea de integrar investigadores externos al Comité Editor, lo cual esperamos hacerlo en los próximos meses.

Revisores pares externos a nuestra institución: además de los miembros del Comité Consultivo, invitamos también de manera eventual a investigadores externos (la mayoría extranjeros) a colaborar con nosotros en la revisión de los manuscritos. En el 2017 fueron 63 personas (provenientes de 12 países), a los cuales agradecimos su labor publicando la lista de sus nombres y filiación institucional en el último fascículo de la revista de ese año. 
Consideramos que la colaboración recibida por todos los investigadores antes mencionados han contribuido a mejorar la calidad de los artículos publicados en nuestra revista. Estamos muy agradecidos a todos ellos, su apoyo ha sido valioso. Queremos agradecer también a los integrantes del Equipo Editor y asistentes editoriales, por su compromiso y arduo trabajo; a los autores y lectores de Odontología Sanmarquina que hacen posible que avancemos como revista buscando servir de la mejor manera a la comunidad odontológica internacional con una publicación de calidad y de interés a la profesión.

Hay mucho camino por transitar, sin embargo, los resultados descritos anteriormente nos alientan y nos vuelven optimistas respecto al futuro. Debido a esto, actualmente nos encontramos en el proceso de registro de nuestra revista en el Directory of Open Access Journals y posteriormente nos presentaremos para que sea evaluada buscando su admisión en SciELO.

\section{Referencias bibliográficas}

1. Alperin JP, Rozemblum C. La reinterpretación de visibiidad y calidad en las nuevas poliíticas de evaluación de revistas científicas. Rev Interam Bibliot. 2017;40(3):231-41.

2. Nassi-Calo L. Internacionalización como indicador de desempeńo de revistas en Brasil: el caso de la psicología [Internet]. SciELO en Perspectiva, 2017 [consultado el 15 de mayo 2018]. Accesible en: https://blog.scielo. org/es/2017/03/14/internacionalizacion-como-indicador-de-desempeno-de-revistas-en-brasil-el-caso-de-la-psicologia/

3. Mattos-Vela MA, Cuadrao Zavaleta L. Seguimos avanzando [editorial]. Odontol Sanmarquina. 2017;20(1):3-4.

4. Mattos-Vela MA, Cuadrao Zavaleta L. Revista al servicio de la comunidad científica [editorial]. Odontol Sanmarquina. 2017;20(2):37-38. 